\title{
A Certificação Bandeira Azul e seus Impactos nas Praias do Brasil
}

\author{
Rafaella Soares Espínola \\ Lissa Valéria Fernandes Ferreira ${ }^{b}$ \\ Sergio Marques Junior ${ }^{c}$
}

\section{Resumo}

As certificações ambientais surgem num contexto onde a sustentabilidade vem sendo discutida na gestão de destinos turísticos. Aplicadas às praias e marinas, seguem critérios rigorosos e indicam a qualidade ambiental dos locais certificados, gerando credibilidade nas ações voltadas à sustentabilidade. Neste contexto, esta pesquisa objetiva analisar os impactos da certificação Bandeira Azul nas praias brasileiras a partir da percepção dos representantes de cada praia certificada. Como procedimentos metodológicos, trata-se de um estudo descritivo exploratório de abordagem qualitativa que contou com a aplicação de entrevistas estruturadas com os cinco representantes das praias certificadas no Brasil e coordenação geral do Bandeira Azul nacional. No tratamento dos dados, foi utilizada a técnica da análise de conteúdo (Bardin, 2004) onde os resultados foram ilustrados no formato de quadros. Concluiu-se que a certificação Bandeira Azul pode representar um elemento de diferenciação turística para as praias certificadas, impactando positivamente na imagem do destino, trazendo benefícios econômicos, fomentando a captação de recursos públicos e privados, promovendo a conscientização ambiental dos atores envolvidos (gestores, turistas e comunidades), entre outros.

Palavras-Chave: Certificação ambiental; Praia; Destino turístico; Sustentabilidade; Oferta diferencial.

\section{Abstract \\ The "Blue Flag" Certification and its Impacts on Brazilian Beaches}

Environmental certifications appear in a context where sustainability has been discussed in the management of tourist destinations. Applied to beaches and marinas, they follow strict criteria and indicate the environmental quality of certified locations, generating credibility in actions aimed at sustainability. In this context, this research aims to analyze the impacts of the "Blue Flag" certification on Brazilian beaches in the perception of each beach representatives. As methodological procedures, it is a descriptive exploratory study with a qualitative approach that included structured interviews with the five beaches representatives and general coordination of the national "Blue Flag". In data processing, the technique of content analysis was used (Bardin, 2004) where the results were illustrated in the format of tables. It was concluded that "Blue Flag" certification can

a. Doutoranda em Turismo pela Universidade Federal do Rio Grande do Norte (UFRN). Natal, Rio Grande do Norte, Brasil. E-mail: rafaella.s.espinola@gmail.com

b. Doutora em Administração de Empresas pela Universitat de Barcelona (UB). Docente do Programa de Pós-Graduação em Turismo na Universidade Federal do Rio Grande do Norte (UFRN). Natal, Rio Grande do Norte, Brasil. E-mail: lissaferreira.iadb@yahoo.es

c. Doutor em Agronomia pela Universidade Estadual Paulista Julio de Mesquista Filho (UNESP). Docente do Programa de Pós-Graduação em Turismo na Universidade Federal do Rio Grande do Norte (UFRN). Natal, Rio Grande do Norte, Brasil. E-mail: sergio@ct.ufrn.br 
represent an element of tourist differentiation for certified beaches, positively impacting the image of the destination, bringing economic benefits, promoting the capture of public and private resources, promoting environmental awareness of the actors involved (managers, tourists and communities), among others.

Keywords: Environmental Certification; Beach; Tourist destination; Sustainability; Differential offer.

\section{Resumen}

\section{La Certificación "Bandeira Azul" y sus Impactos en las Playas Brasileñas}

Las certificaciones ambientales aparecen en un contexto donde se ha discutido la sostenibilidad en la gestión de los destinos turísticos. Aplicados a playas y marinas, siguen estrictos criterios e indican la calidad ambiental de localizaciones certificadas, generando credibilidad en acciones orientadas a la sostenibilidad. En este contexto, esta investigación tiene como objetivo analizar los impactos de la certificación "Bandeira Azul" en las playas brasileñas desde la percepción de los representantes de cada playa certificada. Como procedimientos metodológicos, es un estudio exploratorio descriptivo con enfoque cualitativo que incluyó entrevistas estructuradas a los cinco representantes de playas certificadas en Brasil y coordinación general de la "Bandeira Azul" nacional. En el tratamiento de los datos se utilizó la técnica de análisis de contenido (Bardin, 2004) donde se ilustraron los resultados en formato de tablas. Se concluyó que la certificación "Bandeira Azul" puede representar un elemento de diferenciación turística para las playas certificadas, impactando positivamente la imagen del destino, trayendo beneficios económicos, promoviendo la captación de recursos públicos y privados, promoviendo la conciencia ambiental de los actores involucrados (gestores, turistas y comunidades), entre otros.

Palabras clave: Certificación ambiental; Playa; Destino turístico; Sostenibilidad; Oferta diferencial.

\section{INTRODUÇÃo}

Devido às belezas paisagísticas, recursos ambientais e econômicos, a zona costeira tem sido bastante valorizada pela atividade turística. No Brasil, o segmento intitulado "turismo de sol e mar" representa a principal demanda doméstica e internacional, mas vem ocasionando uma série de impactos socioambientais devido à desordenada ocupação e ausência de uma gestão sustentável em muitos destinos.

Neste contexto, existe uma relação contraditória entre turismo e meio ambiente, onde, ao mesmo tempo em que o turismo necessita de um ambiente ecologicamente equilibrado para vender o destino e garantir seu desenvolvimento a longo prazo, também é responsável pelo consumo excessivo de paisagens impactando de forma negativa o ambiente quando provoca problemas como poluição do ar, das águas, lixo, entre outros.

Todavia, a pressão gradual dos governos, ONGs e parcela dos turistas mais conscientes pela incorporação de princípios da sustentabilidade nos produtos, serviços e destinos, têm movimentado ações voluntárias no sentido de promover uma gestão mais sustentável de destinos e praias. Dentre estas iniciativas voluntárias, se destacam as "diretrizes ambientais, códigos de esquemas de conduta e certificação" (Creo \& Fraboni, 2011: 3), sendo a Bandeira Azul a certificação de praias mais conhecida mundialmente. 
A rotulagem ecológica se apresenta como "um método de padronização e verificação de produtos e serviços de conformidade com um conjunto de critérios prescritos", sendo o seu primeiro passo a certificação (Radchenko \& Aleyev, 2011:1).

Os rótulos ou certificações ambientais tem o intuito de indicar a qualidade dos destinos certificados, gerando credibilidade nas ações voltadas à sustentabilidade e sendo associada a uma vantagem competitiva em um contexto onde prevalece, no geral, a padronização de destinos massificados.

Na América Latina, é possível identificar nove tipos de certificações de praias e marinas: Bandeira Azul, Bandeira Azul ecológica, Destino Azul, Ecoplaya, IRAM 41200, NMX-AA-120-SCFI, NTS-TS-0012, Playa Ambiental e Playa Natural (Zielinsky \& Cano, 2014). Neste estudo, optou-se por analisar a única certificação aplicada às praias brasileiras: o selo Bandeira Azul, que corresponde a certificação de maior visibilidade internacional. Deste modo, esta pesquisa objetiva analisar os impactos da certificação Bandeira Azul nas praias brasileiras a partir da percepção dos representantes de cada praia certificada.

Para tanto, a pesquisa foi dividida em quatro partes. Na primeira, trazemos uma breve discussão sobre competitividade e sustentabilidade nos destinos turísticos de modo a contextualizar a certificação ambiental de praias como uma vantagem competitiva. Em seguida, apresenta-se o Programa Bandeira Azul discutindo seus critérios e benefícios para praias certificadas. Na terceira parte, são descritos os procedimentos metodológicos incluindo as técnicas de coleta e tratamento dos dados. E por fim, são discutidos os impactos da aplicação do selo bandeira azul nas praias brasileiras certificadas.

\section{Competitividade e sustentabilidade em destinos turísticos}

Em um contexto mundial onde o turismo é visto como uma das atividades mais importantes do planeta, com números de transações iguais ou maiores que as exportações de petróleo, produtos alimentícios ou automóveis e uma importante fonte de receita para muitos países em desenvolvimento (OMT, 2018), a pressão competitiva oriunda da diversificação entre os destinos vem aumentando juntamente com a pressão dos interesses socioambientais ocasionados pela expansão da atividade e consequente deterioração dos recursos ambientais (Mazaro \& Varzin, 2008).

Ritchie e Crouch (2010), Mazaro e Varzin (2008) já sinalizam para a inclusão da sustentabilidade como um dos fatores decisórios da competitividade dos destinos turísticos. Neste sentido, a competitividade do turismo "requer o tratamento da sustentabilidade como condição estratégica na organização e gestão de destinos e, especialmente, na composição e sobrevalorização da oferta" (Mazaro \& Varzin, 2008, p. 784).

No caso dos destinos turísticos costeiros, onde a oferta é bastante similar do ponto de vista dos atrativos e serviços, bem como na composição de preços, os destinos procuram identificar cada vez mais vantagens competitivas que possam os diferenciar da concorrência nacional e internacional. Neste sentido, uma das estratégias para se obter vantagem competitiva é por meio de "sinais que certifiquem e comuniquem a qualidade fornecida" (Capacci, Scorcu \& Vici, 2015, p. 88) como as certificações ambientais e/ou de qualidade e os rótulos ecológicos. 
Os rótulos ecológicos são ferramentas voluntárias de certificação e garantia da eficiência ambiental de um produto ou serviço que, atualmente, estão sendo aplicados aos destinos turísticos, sobretudo nas praias, de grande relevância para a atividade e segmento de sol e mar. 0 rótulo ecológico se diferencia dos símbolos verdes por ser concedido por um terceiro, "onde os critérios ambientais são determinados de forma independente" (Ryglová, 2007, p. 140), o que garante uma maior credibilidade para o discurso ecológico e de qualidade dos destinos.

Deste modo, as certificações ambientais e de qualidade de destinos turísticos entraram definitivamente no debate sobre atratividade e competitividade. Esta visibilidade dada aos selos em questão é reforçada pelo interesse e apoio da mídia que cobre amplamente os destinos turísticos que se destacam mediante a adoção de selos.

Na Itália, por exemplo, todos os anos os jornais nacionais mais populares como o La Repubblica e La Stampa divulgam a relação das praias certificadas pelo selo Bandeira Azul. Tais certificações buscam reconhecer e promover boas práticas nos destinos turísticos e podem atrair novos segmentos de mercado e consumidores sensíveis às causas ambientais (Capacci et al., 2015).

Os atributos sustentáveis dos destinos entraram na elaboração de alguns modelos de competitividade/sustentabilidade de destinos. A partir de uma perspectiva política, o modelo de Ritchie e Crouch (2010) apresenta sete componentes que influenciam na competitividade/sustentabilidade do destino turístico: ambiente global (macro); ambiente competitivo (micro); recursos principais e atrativos; fatores e recursos de apoio; política de destino, planejamento e desenvolvimento; gerenciamento de destino e qualificadores e intensificadores determinantes. Em um artigo publicado em 2010, estes autores explicam, ao analisar o Brasil, que a vantagens comparativas da nação (baseadas em dotações de recursos como a natureza, a cultura, etc.) somada as suas vantagens competitivas (ligadas a sua eficácia e eficiência) criam a capacidade geral do Brasil competir no mercado (Ritchie \& Crouch, 2010).

No modelo apresentado por estes autores, os componentes do modelo podem ser entendidos, primeiramente, em um ambiente global (macro), onde apresenta as forças ambientais que podem alterar a atratividade de um país e que estão relacionadas com seis grupos principais: economia, tecnologia, ecologia, desenvolvimentos políticos e legais e demografia. Por outro lado, o ambiente competitivo (micro) é formado pela influência das organizações e forças que forma o "trade travel". Um elemento que constitui um dos principais motivadores da visitação de um destino é formado pelos "recursos principais e atrativos" como a "fisiografia e clima, cultura e história, laços de mercado, mix de atividades, eventos especiais, entretenimento e a superestrutura do turismo" (Ritchie \& Crouch, 2010, p. 1054).

Porém, para o turismo se desenvolver, além dos recursos e atrativos, é necessário consolidar "fatores e recursos de apoio" que possam dar uma base para o desenvolvimento da atividade e que impactam diretamente na competitividade, isto inclui elementos como infraestrutura geral, acessibilidade, hospitalidade e vontade política.

Outro elemento do modelo se refere a "Política de destino, planejamento e desenvolvimento", onde se define as estratégias relacionadas à visão, filosofia, posicionamento, monitoramento e avaliação das políticas do destino. Já o componente de "gerenciamento de destino" está concentrado no fortalecimento da qualidade e eficácia dos fatores e recursos de apoio e inclui atividades de marketing, 
informação/pesquisa, financiamento e capital de risco, desenvolvimento de recursos humanos, gestão de visitantes, gerenciamento de crises e a consciência ambiental em relação aos recursos no que os autores intitulam de "resource stewardship" (Ritchie \& Crouch, 2010, p. 1063).

Por último, o componente "qualificadores e intensificadores determinantes" está relacionado a outros elementos que interferem na competividade dos destinos como a sua localização, a interdependência entre eles, a segurança, a consciência e imagem do destino, o custo e a capacidade de carga (Ritchie \& Crouch, 2010).

Outros modelos levam em consideração o novo contexto competitivo onde a sustentabilidade é considerada como um fator de desempenho como As novas coordenadas de Bosch Campubrí et al. (1998) que consideram quatros forças determinadas por um conjunto global e competitivo (consumidores, tecnologia, produção e gestão) onde fatores como a preocupação ambiental são determinantes para o desenvolvimento do turismo. 0 modelo traz uma análise focada no meio ambiente apontando novas possibilidades de gestão baseadas na sensibilidade à degradação da paisagem, proteção dos espaços naturais, entre outros (Mazaro \& Varzin, 2008).

Um modelo similar é representado pela Classificação de Destinos Turísticos The Premier-ranked Tourist Destinations - de Genest e Legg (2003) que constitui uma ferramenta desenvolvida com o apoio do governo do Canadá para medir a competitividade de um destino turístico e sua situação de mercado, servindo como base para o planejamento estratégico do turismo a partir de um "processo analítico sistemático das condições competitividade do destino através de três dimensões de análise: produto, desempenho e futuro, incluindo medidas de sustentabilidade e inter-relações dos fatores" (Mazaro \& Varzin, 2008, p. 800).

Tais exemplos confirmam a importância dada aos atributos sustentáveis nas destinações turísticas, onde a sustentabilidade é considerada um dos fatores determinantes para a competitividade de destinos turísticos, o que pode trazer vantagens competitivas, sobretudo quando esta qualidade ambiental está associada a uma certificação emitida por entidade exterior e independente que garanta a credibilidade das ações e imagem positiva do destino, como é o caso do selo Bandeira Azul.

\section{Certificação de praias e marinas: o programa bandeira azul}

Uma estratégia para garantir a qualidade ambiental das praias e marinas é o Programa Bandeira Azul, conduzido pela organização independente sem fins lucrativos Foundation for Environmental Education (FEE) com o apoio de diversas instituições internacionais. No Brasil é operado pelo Instituto Ambientes em Rede - IAR. (Bandeira Azul, 2018).

Este Programa busca aumentar a conscientização dos cidadãos e dos tomadores de decisão com relação à proteção ao ambiente marinho e costeiro, assim como incentivar a realização de ações que conduzam à resolução dos conflitos existentes (Bandeira Azul, 2018).

O Bandeira Azul teve início em 1987, na Europa, e tornou-se internacional em 2001, com a entrada de cinco países da Bacia do Caribe, África do Sul e Marrocos (Radchenko \& Aleyev, 2011). No Brasil, o programa começou em 2004, e é aberto a certificação de praias marítimas, fluviais e lacustres, marinas e embarcações de Turismo Sustentável, sendo necessário a participação dos municípios e 
instituições representantes de vários segmentos locais para colaborar na implementação do programa (Bandeira Azul, 2018). Atualmente, 4.554 praias e marinas receberam esta certificação em 45 países (Blue Flag, 2018).

Como o foco deste estudo se concentra nas praias, serão discutidos unicamente os critérios deste segmento, uma vez que os critérios para marinas e embarcações de turismo são diferentes e tratados em documentos específicos do Programa. Desta forma, o rótulo ecológico Bandeira Azul visa estimular o desenvolvimento sustentável da zona costeira e é concedido às praias que atendam à 34 critérios em 4 categorias: qualidade da água, educação e informação ambiental, gestão ambiental, segurança e outros serviços na praia.

Quadro 1 - Critérios exigidos às praias pelo selo Bandeira Azul

\begin{tabular}{|c|c|c|}
\hline Categorias & $\begin{array}{l}\text { Quantidade } \\
\text { de critérios }\end{array}$ & Características \\
\hline Qualidade da água & 5 & $\begin{array}{l}\text { Requisitos de amostragem e frequência da qualidade } \\
\text { físico - química da água, etc. }\end{array}$ \\
\hline $\begin{array}{l}\text { Educação e } \\
\text { Informação } \\
\text { ambiental }\end{array}$ & 6 & $\begin{array}{l}\text { Informações sobre o Programa, atividades de educação } \\
\text { ambiental disponibilização de um mapa da praia, } \\
\text { Código de Conduta que reflita as leis e normas relativas } \\
\text { ao uso da praia e arredores, etc.) }\end{array}$ \\
\hline Gestão ambiental & 15 & $\begin{array}{l}\text { Criação de um comitê gestor de praia; gerenciamento } \\
\text { de áreas sensíveis; limpeza; adequada gestão do lixo; } \\
\text { instalações sanitárias em número suficiente e boas } \\
\text { condições de higiene; proibição de camping, circulação } \\
\text { de veículos ou depósito de entulhos; controle rigoroso } \\
\text { do acesso à praia por cães e outros animais domésticos; } \\
\text { boas condições das edificações e equipamentos na praia; } \\
\text { monitoramento de habitats sensíveis, marinhos ou de água } \\
\text { doce; Incentivo aos meios de transporte sustentáveis, etc. }\end{array}$ \\
\hline $\begin{array}{l}\text { Segurança e outros } \\
\text { serviços na praia }\end{array}$ & 8 & $\begin{array}{l}\text { Medidas apropriadas de segurança pública; Equipamentos } \\
\text { de primeiros-socorros; Planos de emergência para } \\
\text { combater riscos por acidentes de poluição; Acesso livre } \\
\text { e seguro até a praia; Fonte de água potável disponível } \\
\text { na praia; Pelo menos uma praia do município deve } \\
\text { estar equipada para receber pessoas com necessidades } \\
\text { especiais; Policiamento na área da praia, etc. }\end{array}$ \\
\hline
\end{tabular}

Fonte - Adaptado de Programa Bandeira Azul Praias - Brasil (2019)

Para garantir a certificação é necessário passar por um processo de inscrição que envolve a avaliação de um júri nacional e posteriormente internacional. De acordo com a Coordenação Nacional Bandeira Azul, no Brasil, o custo de inscrição e de renovação anual é de $\mathrm{R} \$ 4.000,00$ e os demais custos que o município tem para a adequação e manutenção da praia depende de cada caso. A praia é considerada uma candidata quando está trabalhando para atingir todos os critérios da Bandeira Azul. Para garantir que estão cumprindo os critérios, são realizadas auditorias periódicas e em caso de descumprimento a bandeira pode ser removida (Klein \& Dodds, 2017). Quando concedida a certificação, a praia deve hastear a bandeira do programa diariamente indicando que cumpre e está em conformidade com todos os critérios exigidos. Informações sobre o Programa devem ser disponibilizados em uma placa informativa sobre a praia. (Bandeira Azul, 2018). 
Trata-se de uma iniciativa voluntária que possui algumas funções importantes como: incentivar turistas a visitar locais ambientalmente responsáveis; estimular melhorias e novas normas ambientais no domínio do turismo sustentável (Creo \& Fraboni, 2011); promover uma conscientização pública sobre questões ambientais; aumentar a atratividade turística e criar ou melhorar a relação entre governo, usuários públicos e ONGs na zona costeira (Radchenko \& Aleyev, 2011). Além disso, a certificação ecológica "pode criar um sistema de incentivos, monitoramento e fiscalização" das praias (Blackman et al., 2014: 41) e é uma ferramenta útil para seu gerenciamento favorecendo a gestão ambientalmente sustentável (Klein \& Dodds, 2017). Para os usuários das praias, estes selos podem identificar sua qualidade e influenciar na escolha do destino.

A certificação estimula a competitividade dos destinos no sentido de criar um cenário de melhoria contínua na qualidade das praias para manter o selo, válido apenas por uma temporada. Creo e Fraboni (2011) explicam que o Programa Bandeira Azul funciona como uma ferramenta que pode melhorar a gestão costeira de forma holística, com a incorporação de questões ambientais e auxiliando no processo de tomada de decisões dos gestores locais.

Como vantagem competitiva, a certificação traz benefícios como a melhoria da imagem do destino, sendo um elemento de diferenciação "para atrair turismo de qualidade, com significativo retorno econômico para o território" (Creo \& Fraboni, 2011: 5). Como uma ferramenta de comunicação, a ecocertificação pode favorecer a captação de financiamentos e a criação de programas de educação ambiental (Klein \& Dodds, 2017).

Em um estudo sobre a certificação Bandeira Azul na Costa Rica, Blackman et al. (2014) comprovaram que a certificação Bandeira Azul traz benefícios econômicos para a localidade, exemplificando que, na Costa Rica, estimulou a construção de 19 hotéis e 1.628 novos leitos por ano. Isso ocorre porque a certificação garante aos turistas um nível de qualidade, que estimula a demanda nas praias certificadas (Blackman et al., 2014). Porém, o aumento da demanda e atração de novos negócios pode vir a colocar uma pressão adicional no meio ambiente e, paradoxalmente, prejudicar a capacidade das comunidades locais atenderem os padrões de certificação a longo prazo (Blackman et al., 2014), daí a necessidade de fiscalização e monitoramento constante da qualidade dessas praias.

Do ponto de vista econômico, a certificação também afeta positivamente os futuros fluxos de entrada de turistas, sobretudo, estrangeiros. De acordo com pesquisa realizada por Capacci et al. (2015: 88), na costa da Itália, foi constatado que "as bandeiras azuis são eficazes para atrair turistas estrangeiros para destinos costeiros italianos" afetando as decisões de compra desses consumidores. Entretanto, quando analisado o turismo de forma global e a entrada para toda a província citada, e não apenas na costa, nenhum impacto foi encontrado na Itália. O que significa que o impacto sobre os turistas à beira-mar é ocultado pela ação de outros fatores que afetam o turismo como um todo na região e não apenas nas zonas costeiras (Capacci et al., 2015).

Contudo, a eficácia das certificações de qualidade (das praias) na atração de turistas estrangeiros pode ser uma informação importante para os tomadores de decisões e políticas no sentido de investir nos custos associados ao cumprimento dos padrões exigidos na certificação (Capacci et al., 2015). Tais resultados 
devem ser comparados e testados em outros destinos turísticos para se averiguar a convergência ou não das afirmações.

Algumas críticas podem surgir com relação à eficácia da Bandeira Azul na melhoria da gestão costeira ou da sustentabilidade, como o fato de sua execução depender de terceiros (e não os que garantem a certificação); a ação pode não se estender ao destino como todo e os altos custos para conseguir a certificação (infraestrutura, taxas anuais, monitoramento, etc.) representam uma grande dificuldade para a adesão de muitas praias nos países em desenvolvimento. Mas, ainda assim, é inegável a sua contribuição para a conscientização ambiental, gestão sustentável de destinos turísticos e sua competitividade. Vale destacar ainda que, como a questão da sustentabilidade presente na certificação representa apenas um dos componentes da competitividade do destino, é necessário considerar outros elementos e ressaltar que este não é o único fator influenciador na escolha do destino.

\section{METODOLOGIA}

Esta pesquisa, de abordagem qualitativa, exploratória e descritiva trata de um estudo de caso sobre as certificações de praias no Brasil. A escolha pelo selo "Bandeira Azul" como objeto de estudo é fruto de uma pesquisa bibliográfica sobre as principais certificações de praias aplicadas na América Latina, onde o selo "Bandeira Azul" se mostrou o mais relevante por se tratar de uma certificação internacional aplicada em praias de diversos países do mundo e por ser a única certificação de praia aplicada às praias brasileiras.

Na primeira etapa da pesquisa, buscou-se identificar a existência destas certificações mediante consulta de artigos científicos publicados e revisados por pares no portal de periódico CAPES no período de junho a julho de 2019. Em seguida, partiu-se para a coleta de informações no site oficial do programa Bandeira Azul para compreender os critérios da certificação e os locais certificados no Brasil ( 5 praias, 4 marinas e uma embarcação de turismo sustentável). Como o foco desta pesquisa são os destinos turísticos, optou-se por realizar uma amostra por conveniência com as 5 praias certificadas.

Na segunda fase da pesquisa, foi realizada uma entrevista estruturada por e-mail com a Coordenação Nacional Bandeira Azul no Brasil para compreender o surgimento do selo no Brasil, os critérios utilizados, os locais certificados, as perspectivas futuras, o responsável pela adesão e cumprimento dos critérios, as principais motivações das praias que buscam este tipo de certificação, o impacto no turismo local e o impacto na competitividade dos destinos turísticos.

Outra entrevista estruturada foi realizada com os representantes da certificação Bandeira Azul de cada praia certificada considerando as seguintes variáveis: data da certificação, motivações para conseguir a certificação Bandeira Azul, vantagens percebidas com a certificação, impacto da certificação no fluxo de turistas, impacto na imagem/marketing da praia ou destino, impacto econômico, impacto ambiental e impacto na competitividade do destino turístico.

Todas as entrevistas foram realizadas por e-mail em agosto de 2018. Vale ressaltar que foram realizadas diversas tentativas por telefone para identificar os representantes do programa em cada praia certificada por meio das secretarias 
de turismo e meio ambiente locais. Neste contexto, apenas uma secretaria de turismo prestou informação sobre o programa local, as demais certificações estavam ligadas as secretarias de meio ambiente, e as secretarias de turismo não participavam ou não sabiam informar sobre o programa, o que demonstra uma falta de diálogo entre as duas áreas que são essenciais para a condução eficaz deste tipo certificação.

No tratamento dos dados, optou-se pela análise de conteúdo (Bardin, 2004) mediante o processo de categorização (Dencker, 2007). A análise de conteúdo é baseada na decodificação de um conteúdo de mensagens em variáveis que possam ser classificadas e agrupadas por temas (Richardson \& Peres, 1999). Neste caso, as informações oriundas das entrevistas foram decodificadas e agrupadas em categorias temáticas a partir das variáveis supracitadas anteriormente. Os principais dados foram ilustrados na forma de quadros.

\section{RESULTADOS E dISCUSSÃO: A CERTIFICAÇÃO BANDEIRA AZUL NAS PRAIAS BRASILEIRAS E SEUS IMPACTOS}

O programa Bandeira Azul é operado, no Brasil, pelo Instituto Ambientes em Rede, localizado em Florianópolis/SC. De acordo com a coordenadora nacional do Bandeira Azul no Brasil, este selo socioambiental, concedido a praias, marinas e embarcações de turismo sustentável que cumprem os critérios do programa surgiu no Brasil, em 2006, quando o Instituto Ambientes em Rede foi oficialmente aceito como representante da Foundation for Environmental Education.

Na temporada 2017/2018 foram certificadas, no Brasil, cinco praias, quatro marinas e uma embarcação de turismo sustentável. As praias certificadas foram: Praia do Tombo no Guarujá/SP; Prainha no Rio de Janeiro/ RJ, Praia Grande em Governador Celso Ramos/SC; Lagoa do Peri em Florianópolis/SC; Praia de Ponta de Nossa Senhora do Guadalupe e Ilha do Frade em Salvador/BA. No quesito Marinas, foram certificadas: Marina Costabella, em Angra dos Reis/RJ; Marinas Nacionais, em Guarujá/SP; Iate Clube de Santa Catarina, em Florianópolis/SC e Marina Kauai, em Ubatuba/SP. O programa ainda certificou uma embarcação de turismo sustentável: Água Viva Mergulho, em Florianópolis/SC (Bandeira Azul, 2018).

Na fase piloto do programa, onde a praia, marina ou embarcação tem até dois anos para cumprir os critérios e requerer a certificação estavam inscritos 15 candidatos para a próxima temporada (nove praias, cinco marinas e uma embarcação de turismo sustentável), situados nos estados da Bahia, Rio de Janeiro, Santa Catarina, São Paulo e Paraíba (Bandeira Azul, 2018).

0 responsável pela adesão e cumprimento dos critérios, no caso de praias, é a prefeitura municipal e no caso de marinas e embarcações é o dono da empresa. Para a coordenadora do Bandeira Azul no Brasil, as principais motivações das praias que buscam este tipo de certificação são a promoção e o desenvolvimento do turismo, confirmando que esta certificação traz impactos positivos para o turismo local e para competitividade dos destinos turísticos.

Nos caso das praias certificadas, foco deste estudo, as entrevistas com os representantes das cinco praias certificadas no Brasil mostraram que as mesmas levaram em torno de 1 a 2 anos para serem certificadas, sendo que a mais antiga deste grupo possui certificação desde 2010 (Praia do Tombo - Guarujá - SP), 
seguida pela Prainha no Rio de Janeiro-RJ (2011), Praia Grande em Governador Celso Ramos/SC (2015), Lagoa do Peri em Florianópolis/SC (2015) e Ponta de Nossa Senhora do Guadalupe em Salvador/BA (2016). No que se refere as motivações para conseguir a certificação Bandeira Azul (Quadro 2), o representante da Prainha citou o reconhecimento internacional e a referência em sustentabilidade para as praias como principais motivações. Para a representante da Praia Grande a principal razão é que a Bandeira Azul "trouxe e trará sempre e um ótimo desenvolvimento turístico para a cidade". Para a Lagoa do Peri a motivação estaria relacionada ao reconhecimento em qualidade ambiental, uma vez que a "Unidade de Conservação Municipal onde fica a praia certificada, já tinha as condições necessárias (infraestrutura, qualidade de água, práticas de Educação Ambiental e segurança)" para adquirir a certificação, "restando apenas a construção de um banheiro adaptado para portadores de necessidades especiais", que foi realizada para cumprir todos os critérios exigidos. Na Praia do Tombo, a motivação do Município de Guarujá em realizar a inscrição no programa surgiu devido a "mudança de comportamento e de entendimento sobre a necessidade de se adotar uma nova postura em relação ao patrimônio de um município", a busca por uma maior qualidade de vida além da "busca de produtos e serviços comprometidos com o meio ambiente" por parte de muitos consumidores e turistas. Em Ponta de Nossa Senhora do Guadalupe, a iniciativa surgiu pela Fundação Baía Viva (uma instituição sem fins lucrativos) "para incentivar o turismo sustentável como principal vocação econômica da região".

Isto significa que o reconhecimento da qualidade ambiental e a busca por um turismo mais sustentável seriam as principais motivações percebidas pelos gestores das praias certificadas, o que pode atrair novos segmentos de mercado e consumidores que valorizam às questões ecológicas (Capacci et al., 2015).

Quando questionados sobre as vantagens percebidas com a certificação, todos os representantes confirmaram que o selo Bandeira Azul traz vantagens para as praias certificadas. Dentre as vantagens percebidas destacam-se uma maior assistência do poder público, que precisa investir recursos em infraestrutura na praia para se adequar aos critérios exigidos; o reconhecimento da qualidade ambiental por parte da comunidade e turistas; a melhoria na qualidade de vida local, a criação de uma consciência ambiental por parte dos turistas e moradores; maior visibilidade e divulgação da praia e equipes envolvidas; aquecimento da economia através de aumento dos negócios da região; valorização dos imóveis; mudança no perfil do turismo para sustentável e consciente, entre outros. Neste sentido, as entrevistas confirmam a ideia de que a certificação é um elemento de diferenciação que contribui para atrair um turismo de qualidade e melhorar a imagem do destino (Creo \& Fraboni, 2011), trazendo benefícios econômicos (Blackman et al., 2014; Creo \& Fraboni, 2011) e favorecendo a captação de recursos (públicos e privados) e a conscientização ambiental por parte dos gestores públicos, turistas e comunidade local.

Para compreender melhor os possíveis impactos da certificação Bandeira Azul (Quadro 3), foi perguntado aos 5 representantes se a certificação teve algum impacto no fluxo de turistas e todos os entrevistados responderam que houve um aumento no número de turistas, embora um deles (Lagoa do Peri-SC) não associa o aumento do fluxo a este fato isoladamente uma vez que para eles "não há estudos nesse sentido". Em Praia Grande (SC) foi destacado o aumento do número 
de turistas internacionais, especialmente de países como Argentina, Uruguai e Paraguai. Este dado corrobora com o estudo de Capacci et al. (2015), na Itália, que constatou que esta certificação afeta positivamente os futuros fluxos de entrada de turistas para destinos costeiros, especialmente, turistas estrangeiros.

Quadro 2 - Principais motivações para conseguir a certificação Bandeira Azul no Brasil e vantagens percebidas pelos representantes das praias certificadas

\begin{tabular}{|c|c|c|}
\hline Praia certificada & Motivações & Vantagens percebidas \\
\hline Prainha (RJ) & $\begin{array}{l}\text { - Reconhecimento } \\
\text { internacional } \\
\text { - Referência em } \\
\text { sustentabilidade de praias }\end{array}$ & $\begin{array}{l}\text { - Maior assistência do poder público } \\
\text { na disponibilidade de recursos de } \\
\text { infraestrutura para a praia } \\
\text { - Reconhecimento dos frequentadores. }\end{array}$ \\
\hline Praia Grande (SC) & - Desenvolvimento turístico & $\begin{array}{l}\text { - Boas práticas ambientais pelos } \\
\text { moradores e turistas. } \\
\text { - Conscientização com a } \\
\text { limpeza da praia. }\end{array}$ \\
\hline Lagoa do Peri (SC) & $\begin{array}{l}\text { - Reconhecimento em } \\
\text { qualidade ambiental }\end{array}$ & $\begin{array}{l}\text { - Instalação do banheiro adaptado. } \\
\text { - Visibilidade do trabalho do } \\
\text { Departamento de Unidades de } \\
\text { Conservação da FLORAM - PMF. }\end{array}$ \\
\hline Praia do Tombo (SP) & $\begin{array}{l}\text { - Mudança de } \\
\text { comportamento } \\
\text { - Maior qualidade de vida } \\
\text { - Busca de produtos e } \\
\text { serviços comprometidos } \\
\text { com o meio ambiente }\end{array}$ & $\begin{array}{l}\text { - Aumento da competitividade turística. } \\
\text { - Aumento dos usuários da praia. } \\
\text { - } \text { Envolvimento maior da comunidade. } \\
\text { - Valorização dos imor } \\
\text { - da praia em } 35 \% \text {. } \\
\text { - Aumeis na região } \\
\text { - } \text { ambiento da consciên por parte dos turistas e } \\
\text { - } \text { Melhoria na qualidade de vida. } \\
\text { - Aumento da qualidade } \\
\text { - Ambiental costeira. } \\
\text { - Mudanento na oportunidade de negócios } \\
\text { turismo (sustentável e consciente). }\end{array}$ \\
\hline $\begin{array}{l}\text { Ponta de Nossa } \\
\text { Senhora do } \\
\text { Guadalupe (BA) }\end{array}$ & $\begin{array}{l}\text { - Incentivar o } \\
\text { turismo sustentável }\end{array}$ & - Aquecimento na economia \\
\hline
\end{tabular}

Fonte - Dados do estudo (2018)

Sobre o impacto da certificação na imagem e marketing do destino, todos os entrevistados concordaram que houve um impacto positivo na imagem da praia associada à certificação, sobretudo mediante a divulgação de matérias na mídia convencional e reconhecimento internacional das praias certificadas. Creo e Fraboni, (2011) e Klein e Dodds (2017) já indicavam esta relação positiva na imagem no destino que pode auxiliar, inclusive, na captação de financiamentos e programa de educação ambiental. Todavia, em duas praias não foi detalhado o tipo de impacto percebido. 
Assim como no estudo da certificação Bandeira Azul realizado na Costa Rica por Blackman et al. (2014), todos os entrevistados também concordaram que a certificação traz benefícios econômicos para a localidade, especialmente no comércio, na valorização do ponto e mediante maior transferência de renda com o aumento do fluxo de turistas. Neste aspecto, apenas um representante citou um impacto econômico negativo: as elevadas taxas para garantir a certificação Bandeira Azul. Em duas praias foi confirmado o impacto econômico positivo sem exemplos concretos.

Questionados se a certificação trouxe algum impacto ambiental positivo ou negativo, todos os respondentes concordaram que o selo trouxe impactos positivos como a melhoria na qualidade de vida, o aumento da conscientização dos residentes e turistas, incentivo na estruturação de Unidade de Conservação (caso da Lagoa do Peri), incentivo em um melhor uso da praia determinando sua capacidade de carga e melhoria da qualidade ambiental costeira. Na praia Ponta de Nossa Senhora do Guadalupe, nenhum exemplo foi dado, apenas confirmou-se o impacto positivo.

Por fim, avaliando a percepção dos representantes de cada praia sobre a relação entre a certificação Bandeira Azul e a competitividade do destino turístico, as entrevistas apontaram que 3 dos 5 entrevistados consideram que a certificação impacta de forma positiva na competitividade dos destinos, uma vez que o selo proporciona qualidade em vários aspectos e as praias certificadas possuem um ambiente com serviços mais estruturados e meio ambiente preservado. Um entrevistado não respondeu e outro considerou que não existe uma relação direta entre a certificação das praias e a competitividade do destino, destacando que não há estudos sobre isso e que esta não implica na escolha do lugar, que é incrível, independentemente de outros fatores.

Comparando com outros países, o Brasil ainda possui poucas certificações Bandeira Azul (Figura 1), o que demonstra que é preciso avançar no quesito sustentabilidade e qualidade das praias. 0 que se pode afirmar é que a certificação pode vir a impactar de forma positiva na competitividade dos destinos a partir de todos os benefícios citados pelos representantes das praias, mas ainda é necessária uma maior articulação entre as secretarias de turismo e meio ambiente para tornar a certificação uma estratégia de mercado a partir do marketing ambiental das praias certificadas. 


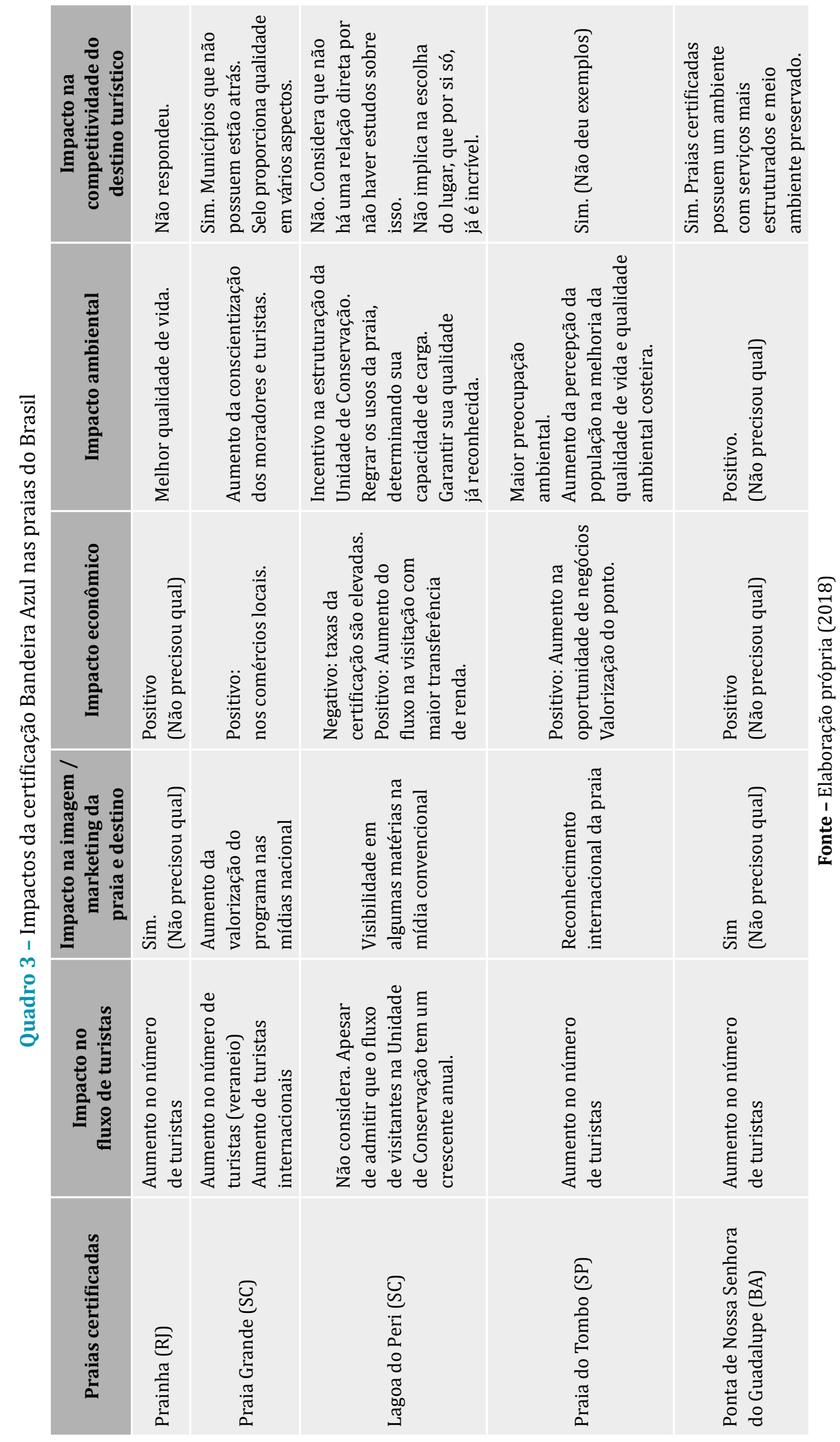




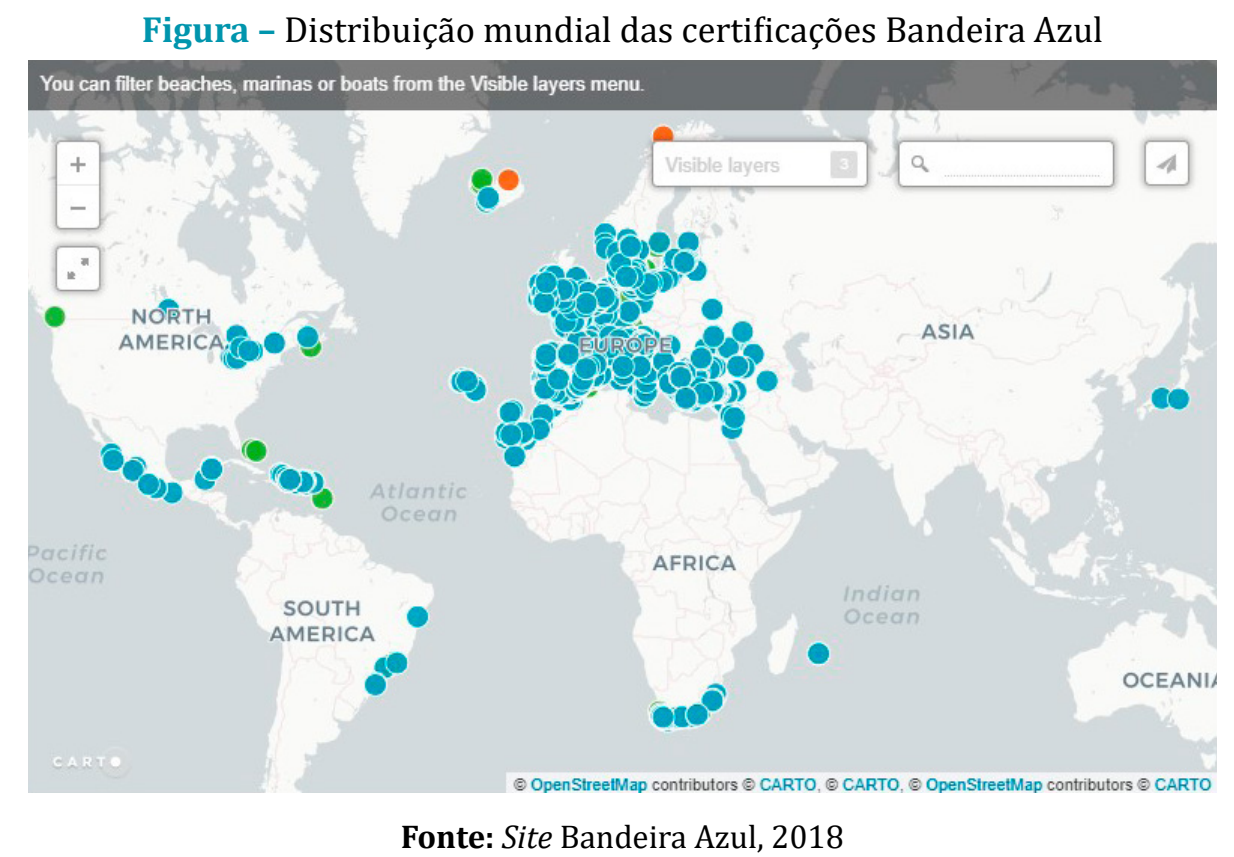

É interessante destacar que, a nível internacional, os continentes que mais possuem certificações Bandeira Azul (Europa e América do Norte) são também os mais competitivos no Ranking Global de Competividade, sendo a Espanha, atualmente, o país mais competitivo no mundo. No Brasil, isto ainda não acontece, uma vez que as praias certificadas não são necessariamente as mais competitivas. Aliado a isto, a carência de infraestrutura básica e/ou turística em muitos destinos e a falta de continuidade entre as políticas públicas de turismo ainda são grandes entraves para o desenvolvimento de um setor mais competitivo a nível internacional e doméstico.

De uma forma geral, os dados coletados demonstram, como na maioria dos estudos citados em outros países, que o selo Bandeira Azul pode favorecer o aumento no fluxo de turistas, impactando positivamente na imagem, na economia local e no meio ambiente dos destinos, o que pode representar uma vantagem competitiva para estes destinos costeiros e melhorar sua competitividade. Mas como a competitividade dos destinos depende de vários fatores (Ritchie \& Crouch, 2010; Mazaro \& Varzin, 2008) esta deve ser complementada com outras estratégias para contribuir de forma mais efetiva na escolha do destino turístico por parte dos turistas.

\section{CONSIDERAÇÕES FINAIS}

Em um contexto onde o discurso ambiental está em alta, e é, inclusive, banalizado nas políticas públicas e nas estratégias de marketing de destinos, a certificação representa então uma forma de garantir a veracidade, o compromisso ambiental e de qualidade das praias avaliadas, o que impacta positivamente nos destinos turísticos costeiros.

No Brasil, nas cinco praias certificadas pelo Programa Bandeira Azul, foi possível constatar, na percepção dos entrevistados, que a certificação trouxe diversos benefícios como uma imagem positiva do destino certificado, o aumento no fluxo de 
turistas, o aquecimento da economia, melhorias na qualidade ambiental e de vida local, entre outros, o que trouxe vantagens competitivas para os destinos turísticos.

No que se refere ao impacto da certificação na competitividade do destino, 3 dos 5 representantes das praias certificadas consideraram que a certificação impacta positivamente na competitividade do destino, porém ainda é necessária uma amostra maior de praias para confirmar esta hipótese na medida em que mais praias forem sendo certificadas. Além disso, faz-se necessário estudos quantitativos que possam comprovar esta relação, uma vez que não existem dados oficiais sobre esta correlação.

Desta forma, a certificação Bandeira Azul pode representar um elemento de diferenciação turística para as praias certificadas, impactando positivamente na imagem do destino, trazendo benefícios econômicos, fomentando a captação de recursos públicos e privados e promovendo a conscientização ambiental dos atores envolvidos (gestores, turistas e comunidades).

Pelas limitações temporais e de abordagem da pesquisa, futuras pesquisas podem aprofundar os resultados averiguando os impactos desta certificação em outras praias e comparar os resultados com outras temporadas. Recomenda-se ainda a realização de estudos comparativos com outros países e o acompanhamento da qualidade das praias nos locais certificados.

\section{REFERÊNCIAS}

Bandeira Azul (2018). O programa. 10 jun. 2018, http://www.bandeiraazul.org.br/sobre/.

Bardin, L. (2004). Análise de conteúdo. 3a ed. Lisboa: Edições, 70.

Blackman, A., Naranjo, M. A., Robalino, J., Alpízar, F., \& Rivera, J. (2014). Does tourism ecocertification pay? Costa Rica's blue flag program. World Development, 58, 41-52. Referenciado de: <https://doi.org/10.1016/j.worlddev.2013.12.002>. Acesso em 15 jun 2018.

Blue Flag (2018), Pure water, clean coasts, safety and access for all. 30 jun, 2018, http://www.blueflag.global/.

Bosch Campubrí, R., Marco, L. P., Cabado, J. S., \& Riera, F. V. (1998). Turismo e meio ambiente. Madrid: Centro de Estudios Ramon Areces.

Capacci, S., Scorcu, A. E., \& Vici, L. (2015). Seaside tourism and eco-labels: The economic impact of Blue Flags. Tourism Management, 47, 88-96. Referenciado de: <https://doi.org/ 10.1016/j.tourman.2014.09.003>. Acesso em 15 jun 2018.

Creo, C., \& Fraboni, C. (2011). Awards for the sustainable management of coastal tourism destinations: The example of the Blue Flag program. Journal of Coastal Research, 378-381. Referenciado de: <https://doi.org/10.2112/SI61-001.43>. Acesso em 17 jun 2018.

Dencker, A. D. F. M. (2007). Pesquisa em turismo: planejamento, métodos e técnicas. São Paulo: Futura.

Genest, J., \& Legg, D. (2003). Premier-ranked tourist destinations: development of a framework for analysis and its self-guided workbook. Ontario: Turismo del Gobierno de Canadá.

Klein, L., \& Dodds, R. (2017). Perceived effectiveness of Blue Flag certification as an environmental management tool along Ontario's Great Lakes beaches. Ocean \& Coastal Management, 141, 107-117. Referenciado de: < https://doi.org/10.1016/j.ocecoaman.2017.03.001>. Acesso em 17 jun 2018. 
OMT (2018). Why tourism? 05 jan. 2019, http://www2.unwto.org/content/why-tourism.

Programa Bandeira Azul Praias - Brasil. Critérios e notas explicativas. 12 mai. 2020, http://bandeiraazul.org.br/wp-content/uploads/2019/08/CRIT\%C3\%89RIOSBANDEIRA-AZUL-PRAIAS.pdf.

Mazaro, R. M., \& Varzin, G. (2008). Modelos de competitividad para destinos turisticos en el marco de la sostenibilidad. RAC-Revista de Administracao Contemporanea, 12(3), 789-810. Referenciado de: < https://www.scielo.br/pdf/rac/v12n3/09.pdf>. Acesso em 17 jun 2018.

Radchenko, V., \& Aleyev, M. (2011). Blue flag program implementation prospective in Ukraine. Journal of Coastal Research, 52-59. Referenciado de: < https://doi.org/10.2112/ SI61-001.65>. Acesso em 17 jun 2018.

Richardson, R. J., \& Peres, J. A. (1999). Pesquisa social: métodos e técnicas. Atlas.

Ritchie, J. R., \& Crouch, G. I. (2010). A model of destination competitiveness/sustainability: Brazilian perspectives. Revista de Administração Pública, 44(5), 1049-1066. Referenciado de: <https://doi.org/10.1590/S0034-76122010000500003>. Acesso em 17 jun 2018.

Ryglova, K. (2007). Eco-certification as a tool of sustainable tourism. Zemedelska EkonomikaPraha, 53(3), 138. Referenciado de: < https://doi.org/10.17221/489-AGRICECON>. Acesso em 17 jun 2018.

Zielinski, S., \& Díaz Cano, M. (2014). Los esquemas de certificacion de playas turisticas en America Latina: Evaluación del componente socio-cultural y el nivel participativo. Estudios y perspectivas en turismo, 23(1), 156-175. Referenciado de: <https://www. redalyc.org/articulo.oa?id=180729920009>. Acesso em 17 jun 2018.

Recebido em: 24/07/2019

Aprovado em: 08/12/2020

\section{CONTRIBUIÇÕES}

Rafaella Soares Espínola: Definição do problema de pesquisa e objetivos, desenvolvimento da proposição teórica, realização da revisão bibliográfica e fundamentação teórica, escolha dos procedimentos metodológicos, coleta e análise de dados, elaboração de tabelas, gráficos e figuras, redação do manuscrito, adequação do manuscrito às normas da RTA.

Lissa Valéria Fernandes Ferreira: Definição do problema de pesquisa e objetivos, desenvolvimento da proposição teórica, revisão crítica do manuscrito.

Sergio Marques Junior: Definição do problema de pesquisa e objetivos, desenvolvimento da proposição teórica, revisão crítica do manuscrito. 